\title{
Delivery of DNAzyme targeting aurora kinase A to inhibit the proliferation and migration of human prostate cancer
}

This article was published in the following Dove Press journal:

International Journal of Nanomedicine

9 September 2015

Number of times this article has been viewed

\author{
Zhen Xing' \\ Sai Gao' \\ Yan Duan' \\ Haobo Han' \\ $\mathrm{Li} \mathrm{Li}^{2}$ \\ Yan Yang' \\ Quanshun Li'
}

'Key Laboratory for Molecular Enzymology and Engineering of Ministry of Education, School of Life Sciences, Jilin University, ${ }^{2}$ Department of Clinic Library, Changchun Women and Children's Health, Changchun, People's Republic of China
Correspondence: Yan Yang; Quanshun Li Key Laboratory for Molecular Enzymology and Engineering of Ministry of Education, School of Life Sciences, Jilin University, Qianjin Street 2699, Changchun 130012, People's Republic of China

Tel/fax +8643185155200

Email yyan@jlu.edu.cn;

quanshun@jlu.edu.cn
Abstract: Herein, a polyethylenimine derivative $N$-acetyl-L-leucine-polyethylenimine ( $N$-AcL-Leu-PEI) was employed as a carrier to achieve the delivery of DNAzyme targeting aurora kinase A using PC-3 cell as a model. Flow cytometry and confocal laser scanning microscopy demonstrated that the derivative could realize the cellular uptake of nanoparticles in an energydependent and clathrin-mediated pathway and obtain a high DNAzyme concentration in the cytoplasm through further endosomal escape. After DNAzyme transfection, expression level of aurora kinase A would be downregulated at the protein level. Meanwhile, the inhibition of cell proliferation was observed through 3-(4,5-Dimethylthiazol-2-yl)-2,5-diphenyltetrazolium bromide and cell colony formation assay, attributing to the activation of apoptosis and cell cycle arrest. Through flow cytometric analysis, an early apoptotic ratio of $25.93 \%$ and G2 phase of $22.58 \%$ has been detected after $N$-Ac-L-Leu-PEI-mediated DNAzyme transfection. Finally, wound healing and Transwell migration assay showed that DNAzyme transfection could efficiently inhibit the cell migration. These results demonstrated that $N$-Ac-L-Leu-PEI could successfully mediate the DNAzyme delivery and downregulate the expression level of aurora kinase A, triggering a significant inhibitory effect of excessive proliferation and migration of tumor cells

Keywords: gene therapy, DNAzyme, aurora kinase A, $N$-acetyl-L-leucine-polyethylenimine, cell proliferation, cell migration

\section{Introduction}

Prostate cancer is the second most frequently diagnosed cancer in men that severely influences the quality of life, ${ }^{1,2}$ and developing an effective treatment for prostate cancer is a challenging issue to be addressed. In recent years, gene therapy based on specific targets has emerged as a promising technique for treating cancers. ${ }^{3}$ Aurora kinase A is a centrosome-associated kinase that has vitally important regulation function in centrosome maturation and spindle assembly. ${ }^{4}$ Its overexpression has been demonstrated to be highly associated with the progression and malignant phenotypes of prostate cancer. ${ }^{5-7}$ The abnormal expression of aurora kinase A would enhance the Mdm2-mediated p53 ubiquitination and induce the chromosomal instability leading to aneuploidy and oncogenic transformation. ${ }^{8}$ Thus, the knockout or inhibition of aurora kinase A will be a potential strategy for prostate cancer therapy. For instance, over a dozen small-molecule inhibitors of aurora kinase A have been developed and showed preclinical and clinical efficacy and will potentially be employed as treatment options for cancers. ${ }^{9}$

To date, there have been various strategies to achieve gene knockout such as small interfering RNA, ${ }^{10}$ micro-RNA, ${ }^{11}$ antisense oligonucleotide, ${ }^{12}$ and deoxyribozyme 
(DNAzyme). ${ }^{13}$ DNAzymes are single-stranded, synthetic DNA catalysts engineered to comprise a catalytic core of approximately 15 deoxyribonucleotides, and they could bind to complementary sequences through Watson-Crick base pairing and cleave target messenger RNA (mRNA) in an RNase-independent manner. ${ }^{14}$ Compared with small interfering RNA and micro-RNA, DNAzymes possessed excellent features of lower synthetic cost, higher stability, and more flexible rational design, ${ }^{15,16}$ and thus, they could be employed as potential therapeutic molecules to inhibit the cancer-associated gene expression. For instance, DNAzymes targeting $c$-myc have been demonstrated to inhibit the proliferation of tumors both in vitro and in vivo. ${ }^{17,18}$ However, due to the inherent instability and negatively charged backbone, DNAzymes usually possessed limited cellular uptake and bioavailability, ${ }^{19}$ and it is necessary to exploit delivery systems for improving DNAzyme-based therapeutic efficiency.

Nonviral carriers, especially cationic polymers, have been widely used as gene delivery systems owing to their low immunogenicity, high gene-loading capacity, flexible designability, and low production cost. ${ }^{20,21}$ Branched polyethylenimine with a weight-average molecular weight of $25 \mathrm{kDa}$ (PEI25K) has shown excellent properties in gene transfection, as its high positive charge and proton buffering capacity can condense nucleic acids, protect them against nuclease's degradation, and further facilitate the cellular uptake and endosomal escape. ${ }^{22-25}$ However, excessive positive charge of PEI25K can cause the destruction of cell membrane and nonspecific interaction with negatively charged proteins in serum, ${ }^{26}$ which will lead to high cytotoxicity, serum instability, and rapid clearance by reticuloendothelial system. To overcome these disadvantages, chemical modification of PEI25K to improve its transfection efficiency and/ or decrease its cytotoxicity has been widely investigated especially through the grafting of hydrophobic groups or polymers. ${ }^{27-30}$ In our previous research, a derivative $N$-acetylL-leucine-polyethylenimine ( $N$-Ac-L-Leu-PEI) has been constructed through the chemical modification of PEI25K with hydrophobic $N$-Ac-L-Leu, and the carrier possessed favorable transfection efficiency and biocompatibility and could successfully realize the p53 gene delivery to inhibit the proliferation of tumor cells. ${ }^{31}$

In the present research, the derivative $N$-Ac-L-LeuPEI was employed as a carrier to achieve the delivery of DNAzyme targeting aurora kinase A, using prostate tumor cell line PC-3 as a model. The cellular uptake and intracellular distribution of DNAzyme were evaluated by flow cytometry and confocal laser scanning microscopy. Finally, the inhibition of cell proliferation and migration after DNAzyme transfection was systematically investigated.

\section{Materials and methods Materials}

The DNAzyme targeting aurora kinase A, fluorescein isothiocyanate (FITC)-labeled DNAzyme, and inactive DNAzyme were synthesized by Beijing Genomics Institute (Beijing, People's Republic of China) as follows:

DNAzyme (Dz): 5'-TTAACAGGGGCTAGCTACAAC GACCTGAAAT-3';

Inactive DNAzyme (iDz): 5'-TTAACAGGGGCTAAC TACAACGACCTGAAAT-3'.

Branched PEI25K and $N$-Ac-L-Leu were purchased from Sigma-Aldrich (St Louis, MO, USA) and used as received. The derivative $N$-Ac-L-Leu-PEI was constructed according to our previous report ${ }^{31}$ and stored in our laboratory. Dulbecco's Modified Eagle's Medium (DMEM) and fetal bovine serum (FBS) were purchased from Thermo Fisher Scientific (Waltham, MA, USA). 3-(4,5Dimethylthiazol-2-yl)-2,5-diphenyltetrazolium bromide (MTT) and 4,6-diamidino-2-phenylindole were purchased from Amersco (Solon, USA). Lipofectamine ${ }^{\text {TM}} 2000$ and Lyso-Tracker Red were purchased from Thermo Fisher Scientific (Waltham, MA, USA), and polyvinylidene fluoride membrane was obtained from Millipore (Billerica, MA, USA). Annexin V-FITC/propidium iodide (PI) apoptosis detection kit and cell cycle detection kit were purchased from Bestbio (Shanghai, People's Republic of China). The antibodies against matrix metalloproteinase-9 (MMP-9), aurora kinase $\mathrm{A}$, and $\beta$-actin, horseradish peroxidase (HRP)-labeled goat anti-rabbit immunoglobulin G and HRP-labeled goat anti-mouse immunoglobulin G were obtained from Abcam (Hongkong). All the other chemicals were of the highest reagent grade commercially available and used as received.

\section{Gel retardation assay}

The $N$-Ac-L-Leu-PEI/Dz nanocomplexes were prepared by gently mixing the carrier $N$-Ac-L-Leu-PEI and DNAzyme together at different mass ratios and incubated at room temperature for 30 minutes before use. The particle size and zeta potential were determined using a Zetasizer Nano ZS90 (Malvern Instruments Ltd, Malvern, UK). The binding ability of $N$-Ac-L-Leu-PEI with DNAzyme was then assessed by $1.5 \%$ agarose gel electrophoresis in Tris-acetateethylenediaminetetraacetic acid buffer solution $(80 \mathrm{~V}$, 15 minutes). 


\section{Cellular uptake of N-Ac-L-Leu-PEI/Dz nanocomplex}

The cellular uptake of $N$-Ac-L-Leu-PEI/Dz was investigated by flow cytometric analysis. For the assay, PC-3 cells were seeded into a 6 -well plate at a density of $1.5 \times 10^{5}$ cells/well in $2 \mathrm{~mL}$ DMEM containing $10 \% \mathrm{FBS}$ and incubated at $37^{\circ} \mathrm{C}$ for 24 hours. Afterward, the medium was removed, and the cells were washed with phosphate buffer saline (PBS), and $1 \mathrm{~mL}$ DMEM was added into the well. The cells were then incubated with $N$-Ac-L-Leu-PEI/Dz nanocomplex (6:1 wt/wt, $1 \mu \mathrm{g}$ DNAzyme) for 1 hour, 4 hours, and 6 hours. Finally, the cells were collected and analyzed by flow cytometry using a FACS Calibur instrument (BD Biosciences, San Jose, CA, USA). To detect the endocytosis mechanism of $N$-Ac-L-LeuPEI/Dz nanocomplex, three inhibitors were used according to the previous studies: ${ }^{32,33} 10 \mu \mathrm{g} / \mathrm{mL}$ chlorpromazine (Aladdin, Shanghai, People's Republic of China), a clathrin-mediated endocytosis inhibitor; $150 \mu \mathrm{M}$ genistein (Aladdin), a caveolae-mediated endocytosis inhibitor; and $50 \mu \mathrm{M}$ wortmannin (J\&K Scientific Ltd, Beijing, People's Republic of China), a macropinocytosis inhibitor. The inhibitors were added to the medium and incubated for 30 minutes, and then $N$-Ac-L-Leu-PEI/Dz nanocomplex was added into the system. In addition, low temperature was employed for investigating the dependence of endocytosis on energy metabolism. ${ }^{34}$ The cells were collected and analyzed by flow cytometry using a FACS Calibur instrument (BD Biosciences).

\section{Intracellular distribution of N-Ac-L-Leu- $\mathrm{PEI} / \mathrm{Dz}$ nanocomplex}

The PC-3 cells were seeded on sterilized coverslips, which were then put into the wells of 6-well plates $\left(1.0 \times 10^{5}\right.$ cells/well) and incubated for 24 hours before DNAzyme transfection. The wells were incubated with $N$-Ac-L-Leu-PEI/Dz (6:1 wt/wt, $1 \mu \mathrm{g}$ DNAzyme) in $1 \mathrm{~mL}$ serum-free medium for 1 hour and 4 hours, and lysosomes were stained with Lyso-Tracker Red for 0.5 hour. Subsequently, the cells were washed with PBS twice and fixed with $75 \%$ ethanol, and the cellular nuclei were stained with 4,6-diamidino-2-phenylindole. Finally, the coverslips were taken out of well, placed on slides, and analyzed using LSM 710 confocal laser scanning microscope (Carl Zeiss Microscopy LLC, Jena, Germany).

\section{Cell proliferation assay}

The effect of $N$-Ac-L-Leu-PEI/Dz transfection on the cell proliferation was examined by MTT assay. PC-3 cells were seeded into a 96 -well plate at a density of $1.0 \times 10^{4}$ cells/well in $200 \mu \mathrm{L}$ DMEM containing 10\% FBS. After incubating at $37^{\circ} \mathrm{C}$ for 24 hours, the medium was removed, and the cells were washed with PBS twice and treated with $N$-AcL-Leu-PEI/Dz nanocomplex harboring different amounts of DNAzyme in $100 \mu \mathrm{L}$ serum-free DMEM. After 6 hours, the medium was replaced with $200 \mu \mathrm{L}$ DMEM containing $10 \%$ FBS, and the cells were cultured for 24 hours or 72 hours. Subsequently, $20 \mu \mathrm{L}$ of MTT solution ( $5 \mathrm{mg} / \mathrm{mL}$ in PBS) was added to each well, and the plate was incubated for an additional 4 hours. The MTT solution was then removed from each well, and $150 \mu \mathrm{L}$ dimethylsulfoxide was added to dissolve the formazan crystals. The plate was incubated for an additional 10 minutes, and the absorbance at $492 \mathrm{~nm}$ was recorded using a GF-M3000 microplate reader (Shandong, People's Republic of China). The cell viability (\%) was calculated as $A_{\text {sample }} / A_{\text {control }}$, where $A_{\text {sample }}$ and $A_{\text {control }}$ were the absorbance values of the treated and untreated cells, respectively. Herein, the difference between cell viabilities of the carriers ( $N$-Ac-L-Leu-PEI or Lipofectamine $\left.{ }^{\mathrm{TM}} 2000\right)$ and corresponding transfection nanocomplexes was employed to evaluate the effect of DNAzyme transfection on cell proliferation.

\section{Cell colony formation assay}

For the cell colony formation assay, PC-3 cells were seeded into a 6-well plate and transfected with $N$-Ac-L-Leu-PEI/Dz nanocomplex (6:1 wt/wt, $6 \mu \mathrm{g}$ DNAzyme) in $1 \mathrm{~mL}$ serumfree DMEM. After 6 hours, the medium was replaced with DMEM containing 10\% FBS and the cells were further cultured for 24 hours. Then the cells were digested with $0.25 \%$ trypsin solution and seeded into a 6-well plate at a density of $3.0 \times 10^{3}$ cells/well. After being cultured for 2 weeks, the cells were stained with $0.1 \%$ crystal violet, and the purple cluster representing cell colonies were eluted with 33\% acetic acid solution. The absorbance at $578 \mathrm{~nm}$ of eluent was recorded using a GF-M3000 microplate reader (Shandong, People's Republic of China).

\section{Western blotting assay}

The PC-3 cells were transfected with $N$-Ac-L-Leu-PEI/ $\mathrm{Dz}$ in serum-free DMEM for 6 hours and subsequently cultured in DMEM containing 10\% FBS for 24 hours. Then the cells were harvested, washed with ice-cold PBS twice, and lysed with radio immunoprecipitation assay lysis buffer on ice for 2 hours. The lysates were centrifuged at $12,000 \mathrm{rpm}$ for 10 minutes, and the supernatants were collected. For Western blotting analysis, an equal amount of protein was subjected to electrophoresis on sodium dodecyl 
sulfate-polyacrylamide gel electrophoresis and transferred to polyvinylidene fluoride membrane by electroblotting. The membrane was blocked with PBS containing 5\% nonfat milk and $0.1 \%$ Tween-20 (PBST) at room temperature for 1 hour and then incubated with desired antibodies (antiaurora kinase A or anti-MMP-9 antibody) at $4{ }^{\circ} \mathrm{C}$ overnight. After being washed with PBST twice, membranes were incubated with appropriate HRP-labeled secondary antibody at room temperature for 1 hour, and specific proteins were detected by enhanced chemical luminescence (Pierce). The protein expression level was normalized against the $\beta$-actin expression, and relative expression level of proteins was calculated through Tanon 1600 gel-imaging system and Tanon Cis 4.0 software.

\section{Induction of cell apoptosis by DNAzyme transfection}

The cell apoptosis induced by DNAzyme transfection was analyzed using an Annexin V-FITC/PI apoptosis detection kit. PC-3 cells were seeded in a 6-well plate at a density of $2.0 \times 10^{5}$ cells/well and incubated for 24 hours before transfection. The transfection was performed using $N$-AcL-Leu-PEI/Dz nanocomplex (6:1 wt/wt, $6 \mu \mathrm{g}$ DNAzyme) in serum-free DMEM for 6 hours. After incubating in DMEM containing 10\% FBS for 24 hours, cells were harvested, washed with PBS twice, and resuspended in binding buffer according to the manufacturer's protocols. The cells were then incubated with Annexin V-FITC and PI at room temperature for 20 minutes in the dark. The apoptosis was determined by analyzing 15,000 gated cells through FACS caliber (BD Biosciences) and Cell Quest software (BD Biosciences).

\section{Induction of cell cycle arrest by DNAzyme transfection}

For cell cycle analysis, PC-3 cells were seeded in a 6-well plate at a density of $2.0 \times 10^{5}$ cells/well and incubated for 24 hours before transfection. The transfection was performed using $N$-Ac-L-Leu-PEI/Dz nanocomplex (6:1 wt/wt, $6 \mu \mathrm{g}$ DNAzyme) in serum-free DMEM for 6 hours. After incubating in DMEM containing 10\% FBS for 24 hours or 48 hours, the cells were collected, washed with PBS twice, suspended in $0.5 \mathrm{~mL}$ solution containing $10 \mu \mathrm{L}$ RNase A $(25 \mu \mathrm{g} / \mathrm{mL})$ and $10 \mu \mathrm{L}$ PI $(50 \mu \mathrm{g} / \mathrm{mL})$, and incubated at $37^{\circ} \mathrm{C}$ for an additional 30 minutes in the dark. The cell cycle was monitored by analyzing 15,000 gated cells using FACS caliber (BD Biosciences) and ModFitLT 2.0 (Verity Software House, Topsham, ME, USA).

\section{Wound healing assay}

The wound healing assay was performed to evaluate the effect of DNAzyme transfection on the migration of PC-3 cells. Briefly, the cells were seeded into a 24 -well plate at a density of $2.0 \times 10^{4}$ cells/well in $2 \mathrm{~mL}$ DMEM containing $10 \%$ FBS and cultured to $90 \%$ confluence. The cell monolayer was subjected to a mechanical scratch wound using a sterile pipette tip, and the cells were washed with PBS twice. The cells were then treated with $N$-Ac-L-Leu-PEI/Dz nanocomplex in serum-free DMEM for 6 hours and further incubated in 10\% FBS-containing DMEM for different time. The digitized images of wound area were captured with IX71 fluorescence microscopy (Olympus, Tokyo, Japan). Three representative zones were chosen to measure the average length of cell migration at each time point through Image-Pro Plus 6.0 software (Media Cybernetics, Silver Spring, USA).

\section{Transwell migration assay}

The cell migration assay was performed using Transwell chamber (Costar, Corning, NY, USA). The DNAzyme transfection was conducted as described earlier, and then a total of $1.0 \times 10^{5}$ cells were resuspended in $200 \mu \mathrm{L}$ serum-free DMEM and added to the upper chamber with $8-\mu \mathrm{m}$ pores, with $600 \mu \mathrm{L}$ DMEM in the lower chamber. The cell migration was conducted at $37^{\circ} \mathrm{C}$ for 24 hours, and nonmigrating cells on the top of membrane were carefully removed by mechanical wiping. Cells that have migrated to the lower surface of membrane were fixed with $75 \%$ ethanol, stained with $0.1 \%$ crystal violet, and detected in a random objective field (200× magnification) using an IX71 fluorescence microscopy (Olympus, Tokyo, Japan).

\section{Statistical analysis}

All the experiments were performed in at least three individuals with each assay, and the data were presented as mean \pm standard deviation. Significant differences among groups were determined by using the unpaired Student's $t$-test, and $P<0.05$ was considered to be the statistical significance.

\section{Results and discussion Cellular uptake and intracellular distribution of N-Ac-L-Leu-PEI/Dz}

The derivative $N$-Ac-L-Leu-PEI was synthesized by 1-ethyl-3-(3-dimethylaminopropyl)-carbodiimide/ $N$ hydroxysuccinimide-mediated couple reaction between PEI25K and hydrophobic $N$-Ac-L-Leu according to the previous research. ${ }^{31}$ The particle size and zeta potential of 
Table I Particle size and zeta potential of N-Ac-L-Leu-PEI/Dz nanocomplex

\begin{tabular}{lll}
\hline $\begin{array}{l}\text { N-Ac-L-Leu-PEI/Dz } \\
\text { (wt/wt) }\end{array}$ & $\begin{array}{l}\text { Particle } \\
\text { size }(\mathbf{n m})\end{array}$ & $\begin{array}{l}\text { Zeta } \\
\text { potential }(\mathbf{m V})\end{array}$ \\
\hline $\mathrm{I}: 1$ & $190.3 \pm 8.1$ & $14.8 \pm 3.1$ \\
$2: 1$ & $163.0 \pm 6.2$ & $16.4 \pm 2.4$ \\
$4: 1$ & $137.8 \pm 4.9$ & $20.9 \pm 1.6$ \\
$6: 1$ & $98.5 \pm 10.2$ & $23.1 \pm 3.0$ \\
\hline
\end{tabular}

Abbreviation: N-Ac-L-Leu-PEI, N-acetyl-L-leucine-polyethylenimine.

nanocomplex formed by $N$-Ac-L-Leu-PEI with DNAzyme at different mass ratios were determined (Table 1). The nanoparticles could be formed with a size range of 99-190 nm, and the particle size exhibited a decreasing tendency with an increasing ratio of polymer, indicating that DNAzyme was gradually packaged and condensed. Meanwhile, the nanoparticles formed by $N$-Ac-L-Leu-PEI and DNAzyme showed a positively charged state and zeta potential values increased with the increasing ratio of polymer, ranging from $+15 \mathrm{mV}$ to $+23 \mathrm{mV}$. Thus, the particle size and zeta potential made these nanoparticles suitable for efficient endocytosis and further transfection. The binding affinity of $N$-Ac-L-Leu-PEI with DNAzyme was examined by agarose gel retardation assay (Figure 1). It was obviously observed that complete DNAzyme retardation could be achieved at a critical mass ratio of 2.0, indicating the formation of stable $N$-Ac-L-Leu-PEI/Dz nanopolyplex. Compared with plasmid DNA (critical mass ratio of $0.6-0.8$ ) ${ }^{31} \mathrm{~N}$-Ac-L-Leu-PEI exhibited a relatively weaker binding ability for singlestranded oligoDNA segment.

The cellular uptake of $N$-Ac-L-Leu-PEI/Dz nanocomplex was investigated using FITC-labeled DNAzyme through flow cytometry. As shown in Figure 2, intracellular

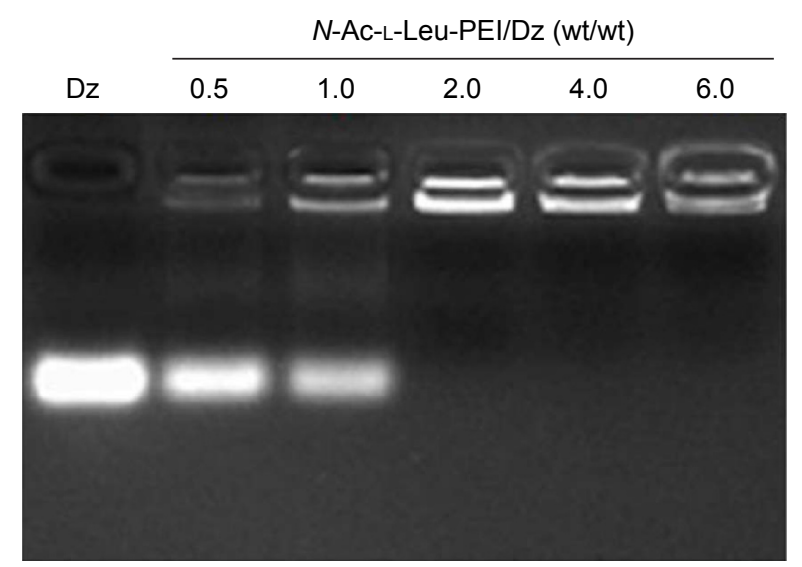

Figure I Gel retardation assay for the nanocomplexes of N-Ac-L-Leu-PEl with DNAzyme at different mass ratios.

Abbreviation: N-Ac-L-Leu-PEI, N-acetyl-L-leucine-polyethylenimine. accumulation of FITC-labeled nanoparticles was clearly observed, and the fluorescence intensity exhibited an increasing tendency with the elongation of incubation time, which was consistent with the quantitative analysis of mean fluorescence intensity. Notably, $N$-Ac-L-Leu-PEI could mediate the cellular uptake of DNAzyme at a higher level than Lipofectamine ${ }^{\mathrm{TM}} 2000$, when the cells were incubated with corresponding nanoparticles for 6 hours. To determine the mechanism of cellular uptake, PC-3 cells were treated with a series of inhibitors and under low temperature, and then the fluorescence intensity of FITC-labeled DNAzyme was analyzed by flow cytometry (Figure 3 ). As the endocytic uptake was an energy-dependent procedure and could be strongly inhibited by low temperature, ${ }^{35,36}$ the cellular uptake of $N$-Ac-L-Leu-PEI/Dz nanocomplex was performed at $4{ }^{\circ} \mathrm{C}$ to check whether the internationalization processed in an energy-dependent manner. In comparison to $37^{\circ} \mathrm{C}$, the cellular uptake of nanoparticles was significantly inhibited at $4^{\circ} \mathrm{C}$, indicating that the $N$-Ac-L-Leu-PEI/Dz nanocomplex was internalized inside the cells via an energy-dependent pathway. To elucidate the cellular uptake pathway, the interaction between $N$-Ac-L-Leu-PEI/Dz nanocomplex and cell membranes was investigated by treating cells with different inhibitors of clathrin-mediated endocytosis (chlorpromazine), caveolae-mediated endocytosis (genistein), and macropinocytosis (wortmannin) and then analyzed by flow cytometry. Clearly, chlorpromazine showed an inhibition on the endocytosis, and relatively lower inhibiting effect was observed in wortmannin-treated group, whereas genistein had no effects on the endocytosis of nanoparticles. Thus, clathrin-mediated endocytosis played a key role in the endocytosis of $N$-Ac-L-Leu-PEI/Dz nanocomplex, and macropinocytosis was also involved in the endocytosis of nanoparticles, whereas the endocytosis was conducted in a caveolae-nondependent pathway.

After the successful endocytosis, the intracellular distribution of $N$-Ac-L-Leu-PEI/Dz was studied through confocal laser scanning microscopy (Figure 4). When the cells were treated with nanoparticles for 1 hour, almost no green fluorescence of FITC-labeled DNAzyme was detected. After 4 hours, green fluorescence could be clearly observed and did not overlap with red fluorescence of Lyso-Tracker Red, indicating that the nanoparticle could achieve the endosomal escape of DNAzyme. As described earlier, the endocytosis of $N$-Ac-L-Leu-PEI/Dz was mainly in a clathrin-mediated pathway, and the nanoparticles would be internalized and localized within endocytic vesicles (endosomes or lysosomes), which produced an environment for the DNAzyme 
A

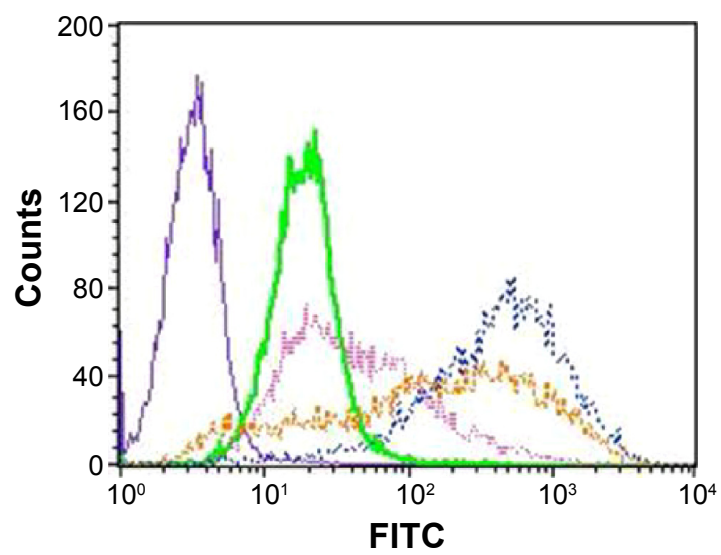

B

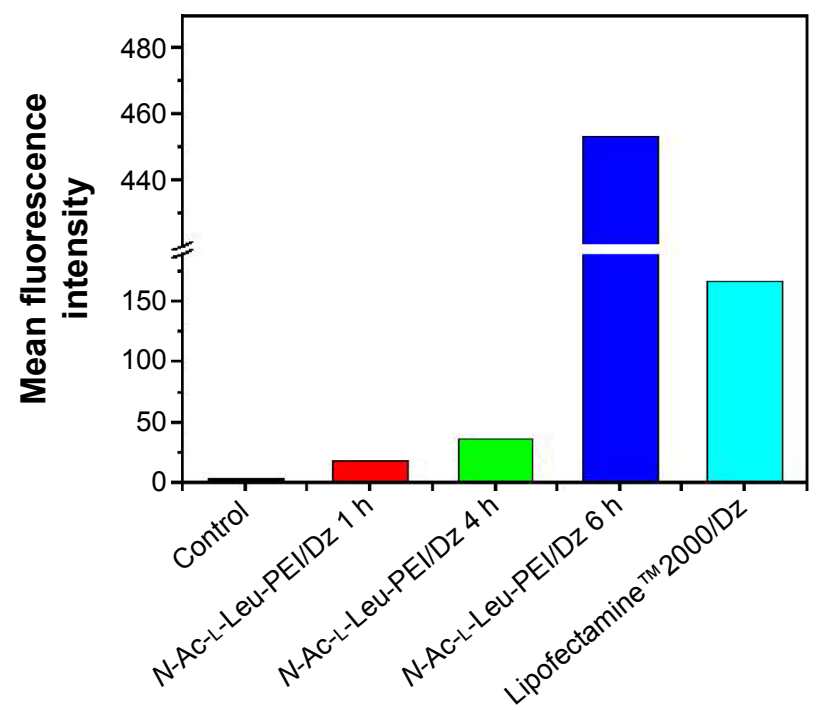

Figure 2 Flow cytometric analysis of the cellular uptake of N-Ac-L-Leu-PEI/Dz (A) and the quantitative measurement of mean fluorescence intensity (B). Abbreviations: N-Ac-L-Leu-PEI, N-acetyl-L-leucine-polyethylenimine; FITC, fluorescein isothiocyanate; h, hour.

degradation. Thus, the derivative $N$-Ac-L-Leu-PEI could not only mediate the efficient endocytosis of DNAzyme but also protect the cargo from degradation, which represented an extremely important step for its action in the cytoplasm before degradation.

\section{Inhibition of cell proliferation by N-Ac-L- Leu-PEl/Dz nanocomplex}

To access the biological role of DNAzyme targeting aurora kinase A, the cell viabilities of PC-3 cells after DNAzyme transfection were studied by MTT assay
A

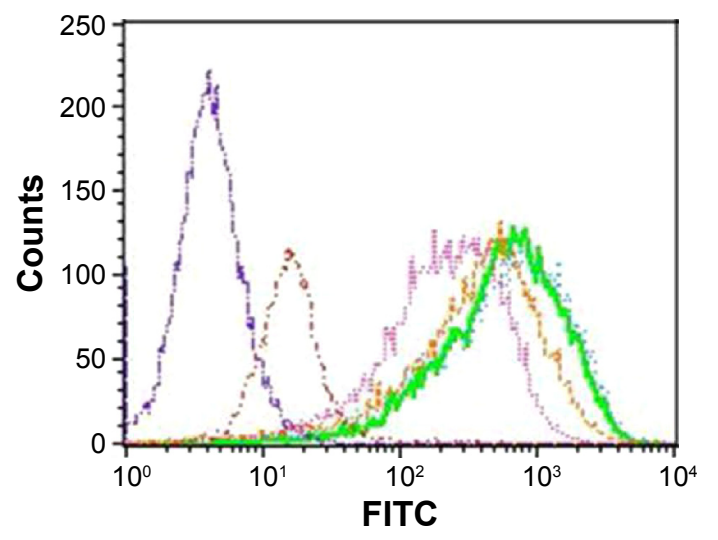

\begin{tabular}{l}
\hline Control \\
N-Ac-L-Leu-PEI/Dz $6 \mathrm{~h}$ \\
$\ldots$ Chlorpromazine \\
$\ldots$ Genistein \\
$\ldots$ Wortmannin \\
$\ldots$ Low temperature
\end{tabular}

B

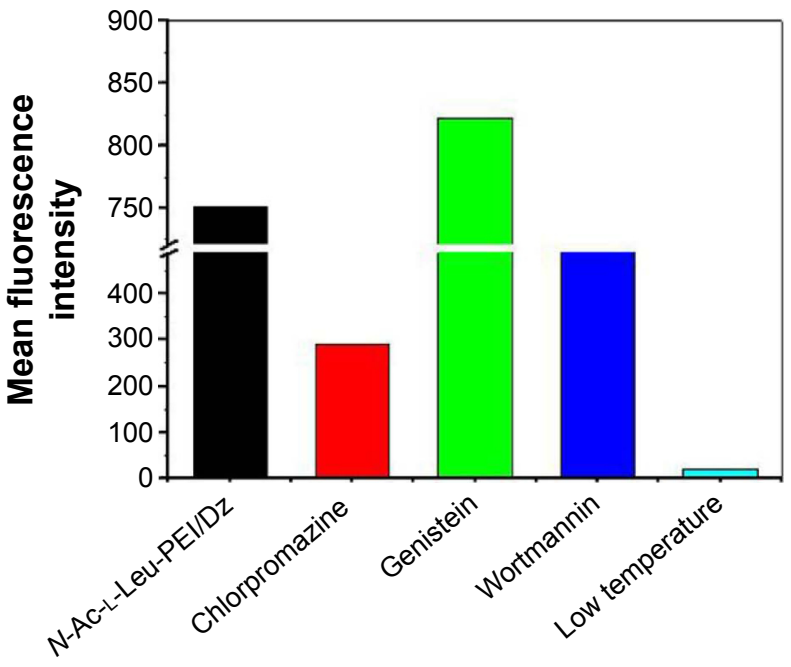

Figure 3 Effects of different inhibitors on the endocytosis of N-Ac-L-Leu-PEI/Dz using flow cytometric analysis (A) and the quantitative analysis of mean fluorescence intensity (B).

Abbreviations: N-Ac-L-Leu-PEI, N-acetyl-L-leucine-polyethylenimine; FITC, fluorescein isothiocyanate; h, hour. 


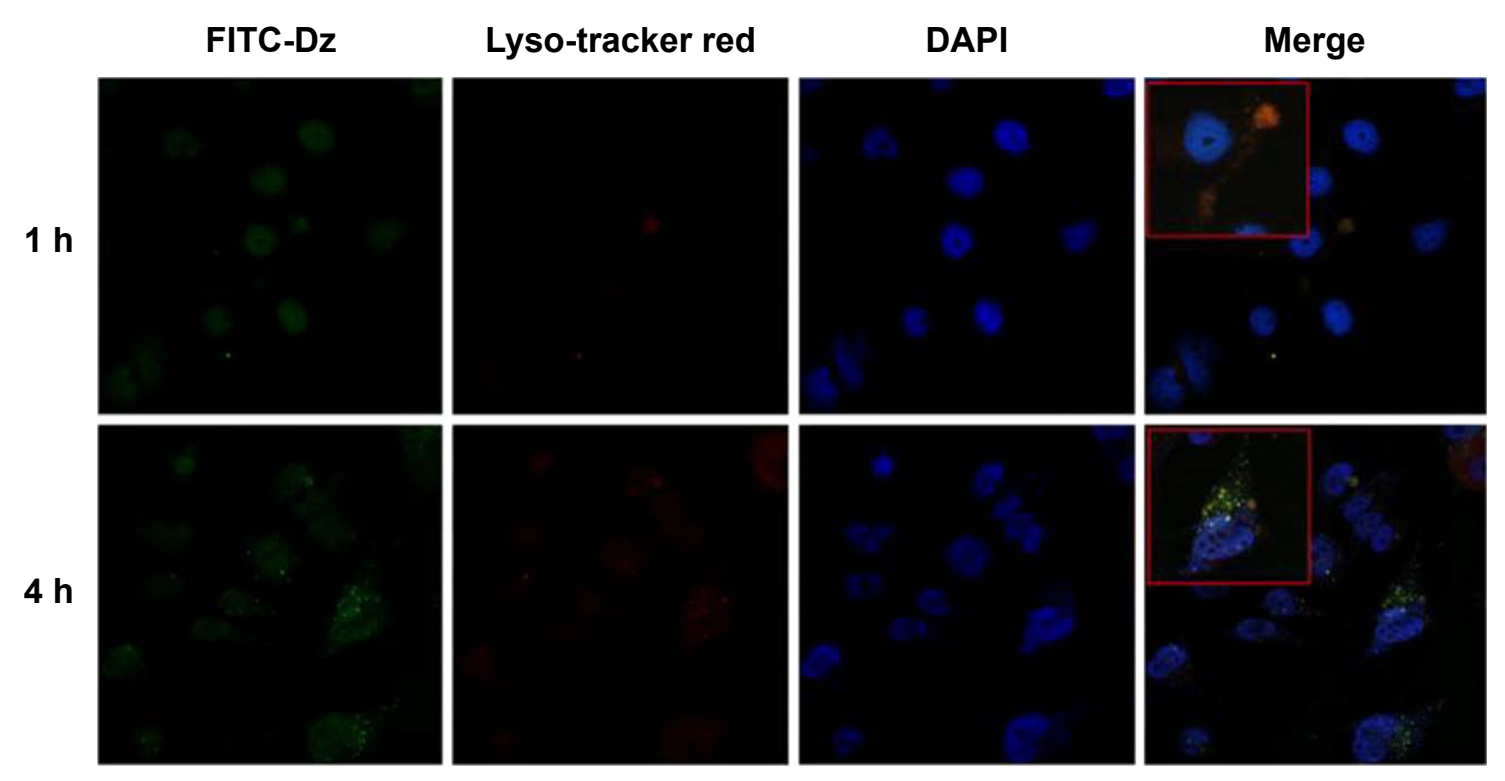

Figure 4 CLSM images of the intracellular distribution of N-Ac-L-Leu-PEI/Dz nanocomplex for I hour and 4 hours.

Notes: Blue, nuclei (DAPI); red, lysosome (Lyso-Tracker Red); green, DNAzyme (FITC-labeled). The boxed areas represent the enlarged cells to show the intracelluar distribution of nanocomplex.

Abbreviations: CLSM, confocal laser scanning microscopy; N-Ac-L-Leu-PEI, N-acetyl-L-leucine-polyethylenimine; h, hour; DAPI, 4,6-diamidino-2-phenylindole; FITC, fluorescein isothiocyanate.

(Figure 5). Compared with naked DNAzyme, $N$-Ac-LLeu-PEI-mediated DNAzyme delivery could highly inhibit the cell viabilities, and the values exhibited a declining tendency with the increasing amount of DNAzyme. For instance, treating with $6 \mu \mathrm{g} / \mathrm{mL}$ DNAzyme for 24 hours would lead to cell viability of $71 \%$, and the concentration was selected for further investigation. Notably, $\mathrm{N}$-Ac-LLeu-PEI/Dz transfection showed a stronger inhibitory effect than commercial reagent Lipofectamine ${ }^{\mathrm{TM}} 2000$ after 24-hour treatment, whereas the inhibition was more obviously in Lipofectamine ${ }^{\mathrm{TM}} 2000 / \mathrm{Dz}$ group after 72 hours. Further, the colony formation assay also showed that compared with control, $N$-Ac-L-Leu-PEI/Dz transfection could obviously achieve the reduction in colony formation, much stronger than Lipofectamine ${ }^{\mathrm{TM}} 2000 / \mathrm{Dz}$ group (Figure 6). All these results demonstrated that N-Ac-LLeu-PEI-mediated DNAzyme delivery could highly inhibit the proliferation of tumor cells. For inactive DNAzyme
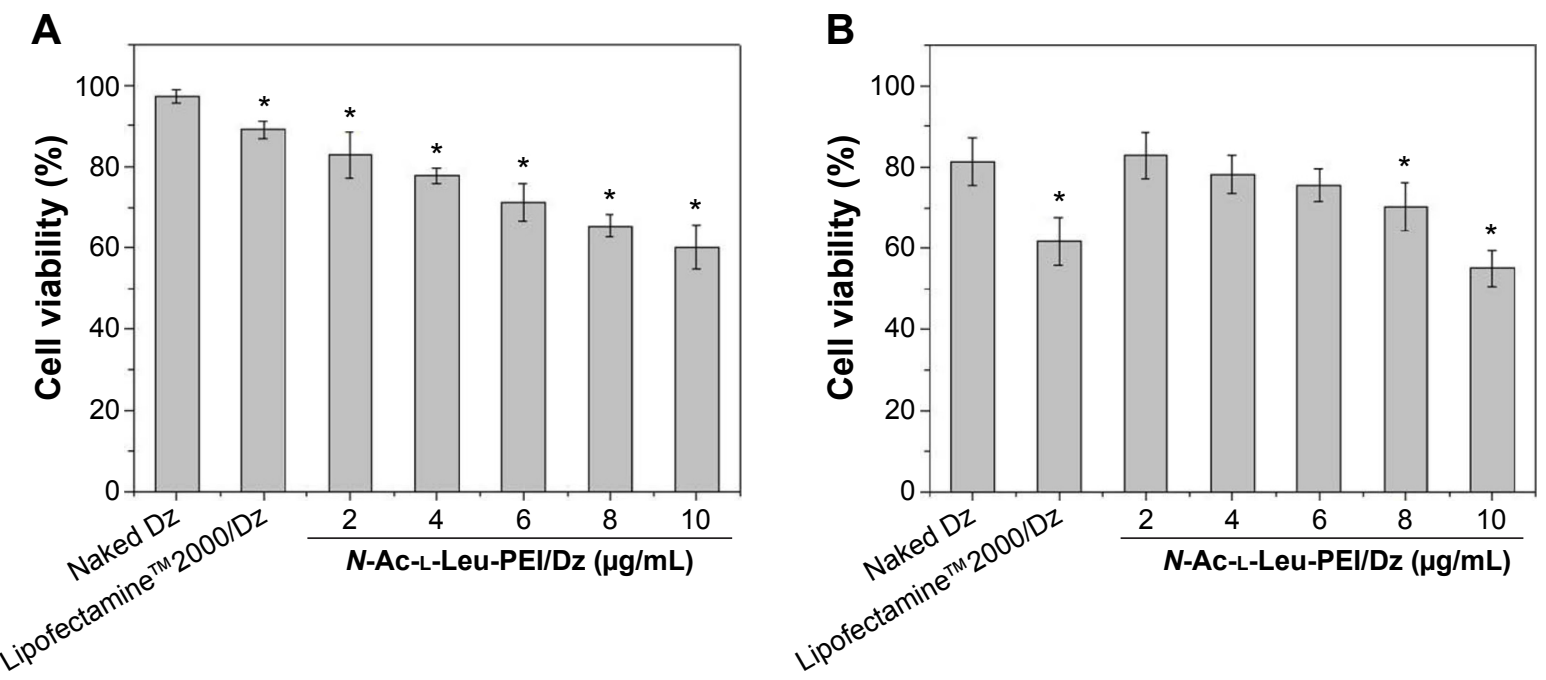

Figure 5 Cell viabilities of PC-3 cells treated with N-Ac-L-Leu-PEl/Dz nanocomplex (wt/wt, 6:I) with different amounts of DNAzyme for 24 hours (A) and 72 hours (B). Notes: The data presented the difference between cell viabilities of the carriers and corresponding transfection nanocomplex. The data were expressed as mean value \pm SD of three experiments, and significance was determined by a Student's $t$-test ( $* P<0.05$, compared with naked Dz group). Abbreviations: $\mathrm{N}$-Ac-L-Leu-PEI, $\mathrm{N}$-acetyl-L-leucine-polyethylenimine; SD, standard deviation. 

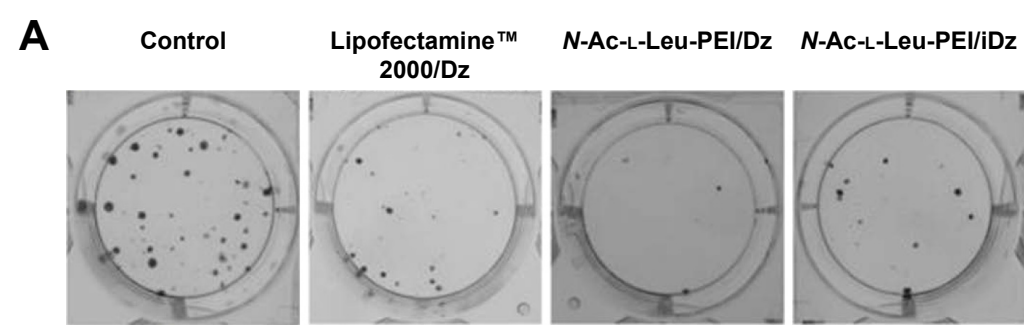

N-AC-L-Leu-PEI

B

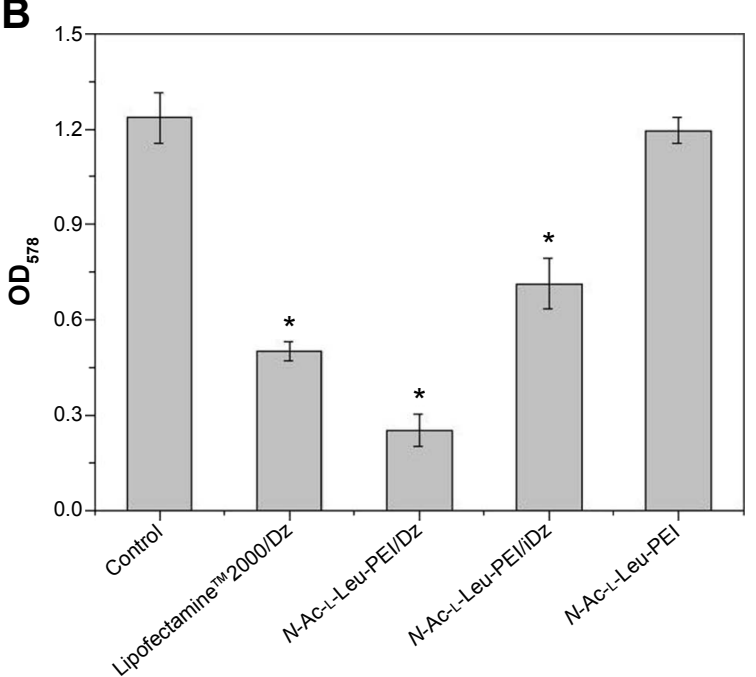

Figure 6 The inhibition of colony formation (A) and the absorbance at $578 \mathrm{~nm}$ of eluent (B) after DNAzyme transfection.

Notes: The data were expressed as mean value \pm SD of three experiments, and significance was determined by a Student's $t$-test $(* P<0.05$, compared with control). Abbreviations: $\mathrm{N}$-Ac-L-Leu-PEI, N-acetyl-L-leucine-polyethylenimine; SD, standard deviation.

(iDz) group, an inhibition of colony formation could be observed, much lower than Lipofectamine ${ }^{\mathrm{TM}} 2000 / \mathrm{Dz}$ and $N$-Ac-L-Leu-PEI/Dz groups. The phenomenon was probably caused by iDz's cleavage of target mRNA due to a simple antisense effect, especially at a high concentration of DNAzyme, which was consistent with previous reports. ${ }^{37,38}$ To elucidate whether the inhibition of cell proliferation was triggered by DNAzyme-induced gene knockout, the expression level of aurora kinase A was evaluated at the protein level through Western blotting. As shown in Figure 7, N-Ac-L-Leu-PEI/Dz and Lipofectamine ${ }^{\mathrm{TM}} 2000$ / Dz groups could efficiently downregulate the expression level of target aurora kinase A, whereas the iDz transfection showed a relatively weak inhibition on the expression of aurora kinase A with $87 \%$ of original expression level. The decreased expression induced by iDz transfection was mainly caused by the simple antisense effect, $, 37,38$ accounting for the slight inhibition of cell proliferation and colony formation described earlier. Meanwhile, DNAzyme delivery mediated by $N$-Ac-L-Leu-PEI could inhibit the expression level of aurora kinase $\mathrm{A}$ in a higher level than Lipofectamine ${ }^{\mathrm{TM}} 2000$ did.
A
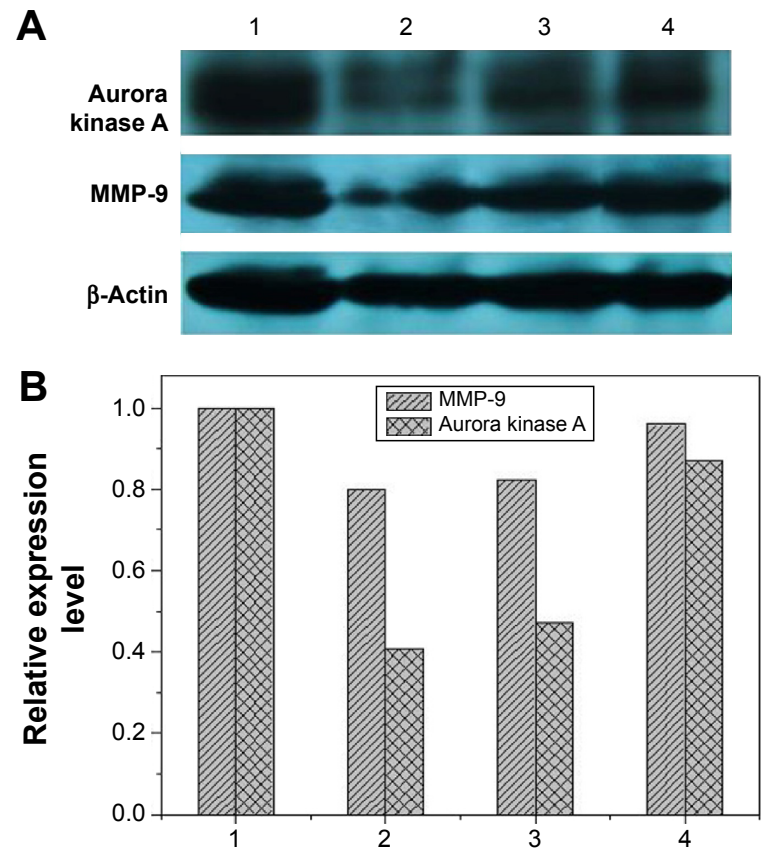

Figure 7 Western blotting $(\mathbf{A})$ and quantitative analysis (B) for the expression level of aurora kinase A and MMP-9 after DNAzyme transfection.

Notes: I: No treatment; 2: N-Ac-L-Leu-PEl/Dz; 3: Lipofectamine ${ }^{\mathrm{TM}} 2000 / \mathrm{Dz}$; and 4: N-Ac-L-Leu-PEl/iDz.

Abbreviations: N-Ac-L-Leu-PEl, N-acetyl-L-leucine-polyethylenimine; iDz, inactive DNAzyme; MMP-9, matrix metalloproteinase-9. 

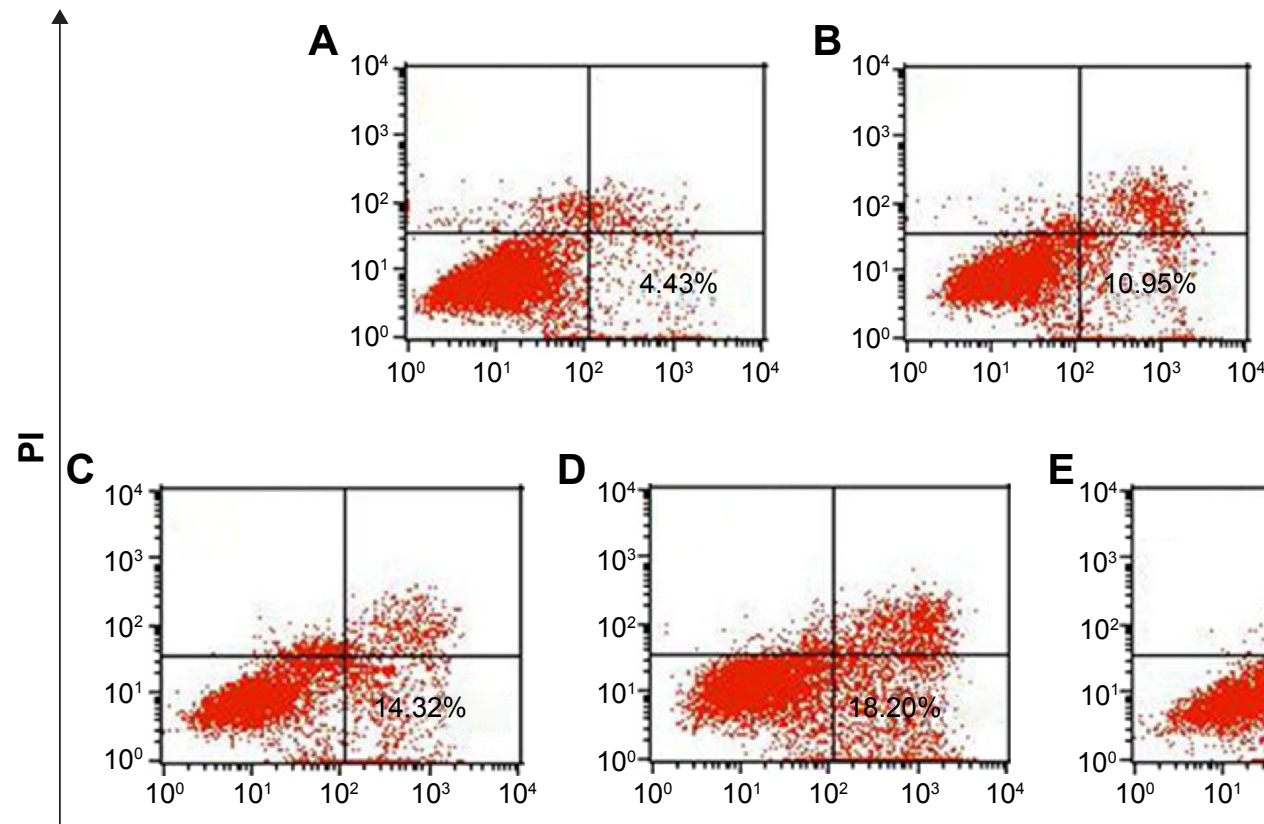

\section{Annexin V-FITC}

Figure 8 Induction of apoptosis in PC-3 cells treated with DNAzyme transfection determined by flow cytometry.

Notes: (A) No treatment; (B) treatment with N-Ac-L-Leu-PEl; (C) treatment with N-Ac-L-Leu-PEI/iDz; (D) treatment with Lipofectamine ${ }^{\mathrm{TM}} 2000 / \mathrm{Dz}$; and (E) treatment with N-Ac-L-Leu-PEI/Dz.

Abbreviations: N-Ac-L-Leu-PEI, N-acetyl-L-leucine-polyethylenimine; iDz, inactive DNAzyme, PI, propidium iodide; FITC, fluorescein isothiocyanate.

Previous research has confirmed that the overexpression of aurora kinase $\mathrm{A}$ is involved in the centrosome abnormality and chromosome instability in various tumors, ${ }^{39}$ and decreasing the expression level of aurora kinase A will trigger the cell apoptosis and cell cycle arrest. The apoptotic death in PC-3 cells induced by DNAzyme transfection was evaluated using Annexin V-FITC/PI staining and followed by FACS analysis (Figure 8). Compared with the control, Lipofectamine ${ }^{\mathrm{TM}} 2000 / \mathrm{Dz}$ and $N$-Ac-L-Leu-PEI/ Dz transfection groups could efficiently induce cell apoptosis, with early apoptotic cells (Annexin V-FITC positive and PI negative) of $18.20 \%$ and $25.30 \%$, respectively. In contrast, the derivative and iDz transfection could trigger relatively weak cell apoptosis with early apoptotic ratios of $10.95 \%$ and $14.32 \%$, respectively. The apoptosis induction mediated by iDz transfection could also be attributed to the partial cleavage of aurora kinase A mRNA owing to the simple antisense effect. ${ }^{37,38}$ Furthermore, the cell cycle analysis was performed via flow cytometry to elucidate whether the antiproliferative effect of DNAzyme transfection was associated with cell cycle arrest (Figure 9). Compared with the control, DNAzyme delivery would lead to a significant increase in the G2 phase, indicating that downregulating the expression level of aurora kinase A could cause the disruption of cell cycle transition and an arrest in G2 phase. In addition, the cell cycle arrest exhibited a dose- and time-dependent manner, and the G2 phase could be obtained with $22.58 \%$ after treating with $N$-Ac-L-Leu-PEI/Dz with $6 \mu \mathrm{g}$ DNAzyme for 48 hours. In conclusion, DNAzyme delivery mediated by $N$-AcL-Leu-PEI could efficiently induce the inhibition of cell proliferation, attributing to the induction of cell apoptosis and cell cycle arrest.

\section{Inhibition of cell migration by N-Ac-L- Leu-PEl/Dz nanocomplex}

In prostate cancers, metastasis-related recurrence is still common and responsible for the prostate cancer-associated mortality. ${ }^{6}$ Herein wound healing and Transwell migration assay were employed to determine whether DNAzyme transfection could affect the cell migration. Compared with the control, the wound size exhibited a slightly reduced trend after DNAzyme delivery, implying that the transfection of DNAzyme targeting aurora kinase A could weaken the cell migration (Figure 10). Additionally, $N$-Ac-L-Leu-PEI/Dz exhibited a highest inhibitory effect, much stronger than Lipofectamine ${ }^{\mathrm{TM}} 2000 / \mathrm{Dz}$ and $N$-AcL-Leu-PEI/iDz groups. Interestingly, the wound size in Lipofectamine $^{\mathrm{TM}} 2000 / \mathrm{Dz}$ transfection group increased after 50 hours, and the unique phenomenon was probably caused 


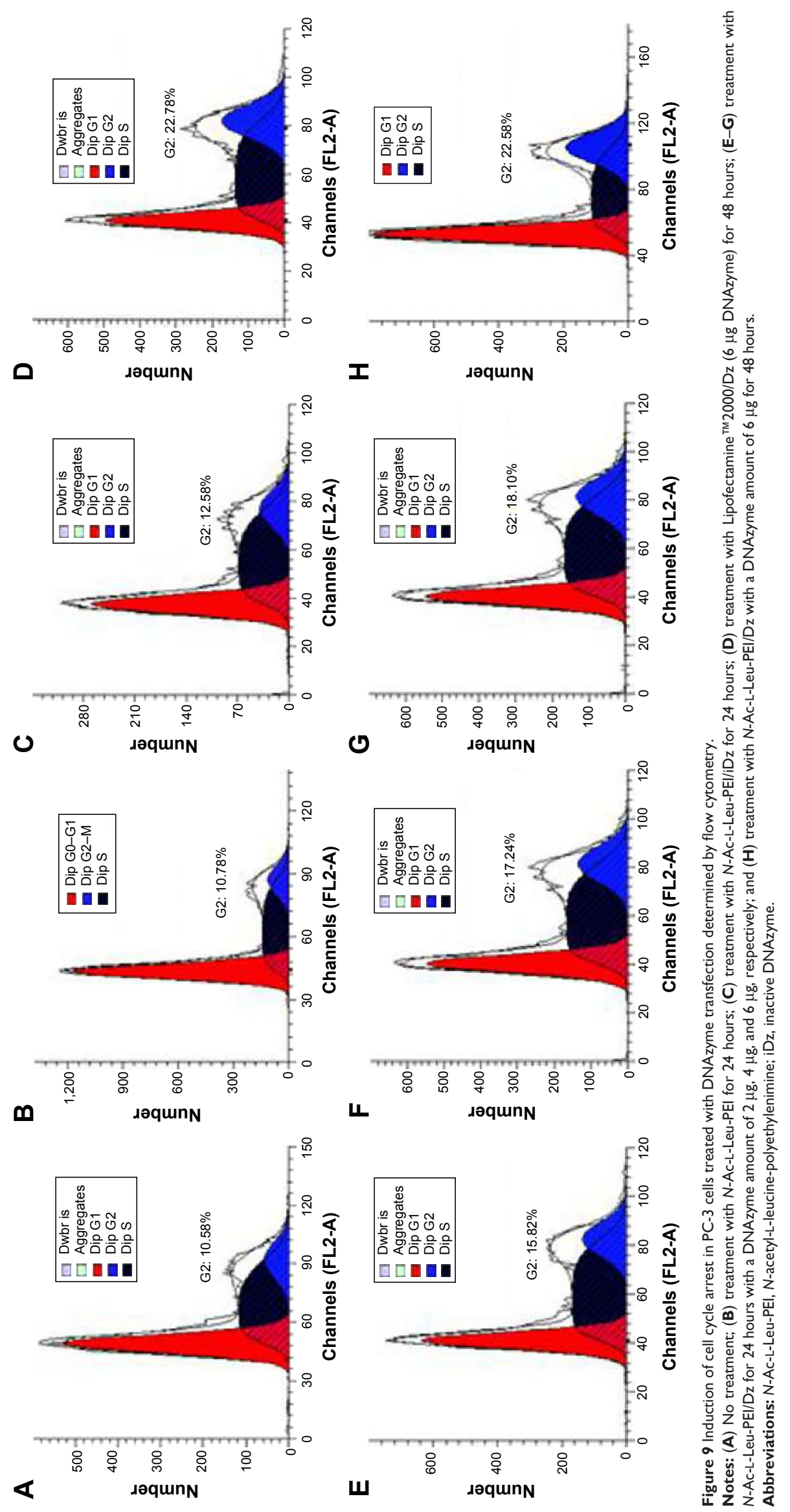


A
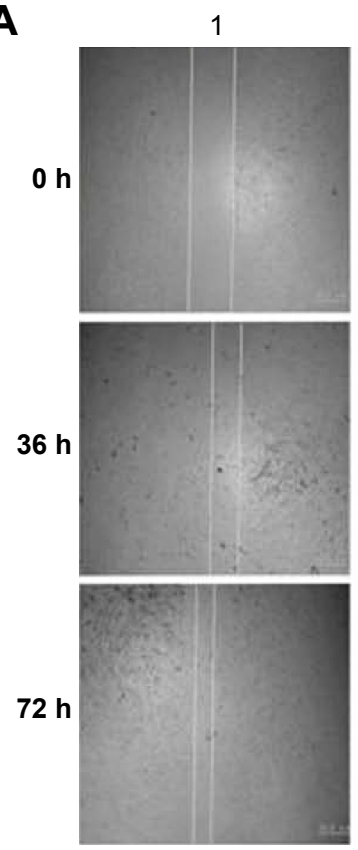

2
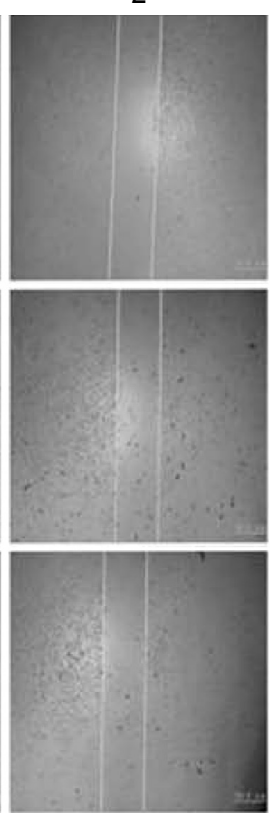

3
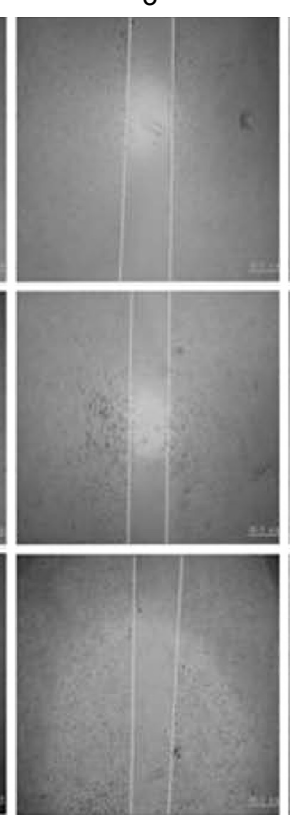

4
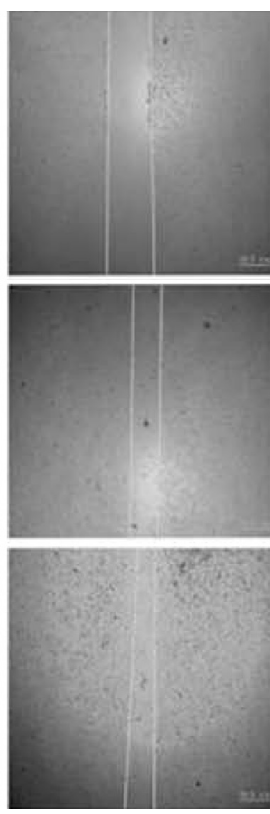

5
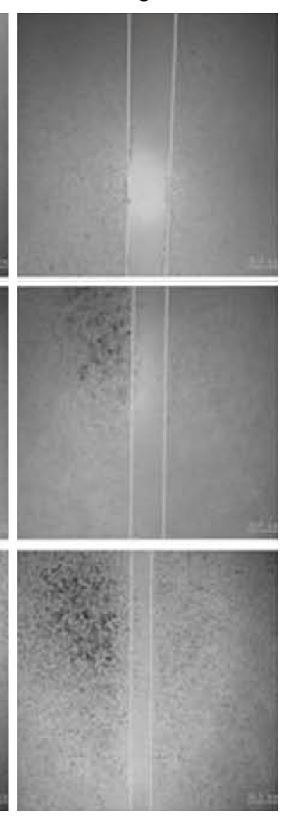

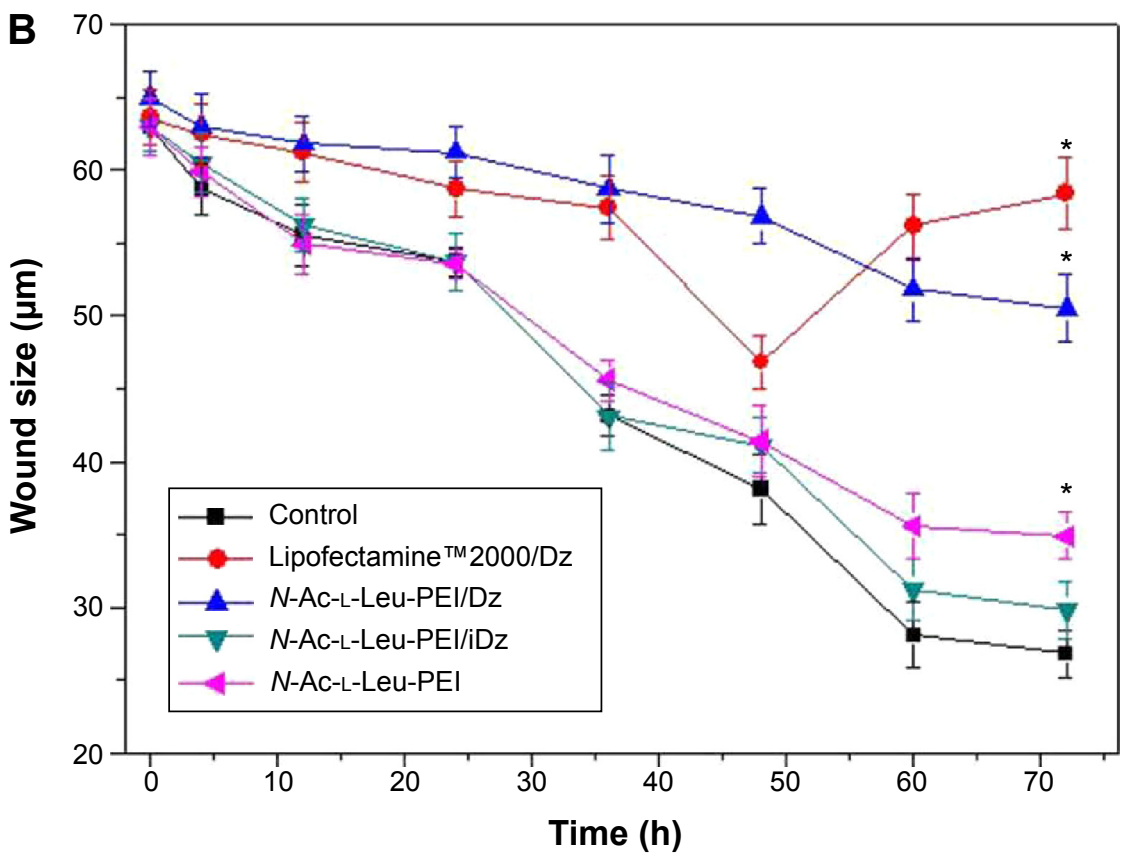

Figure 10 Wound healing assay $(\mathbf{A})$ and quantitative wound size (B) after DNAzyme transfection.

Notes: I: No treatment; 2: Lipofectamine ${ }^{\mathrm{TM}}$ 2000/Dz; 3: N-Ac-L-Leu-PEI/Dz; 4: N-Ac-L-Leu-PEI/iDz; and 5: N-Ac-L-Leu-PEl. The data were expressed as mean value \pm SD of three experiments, and significance was determined by a Student's $t$-test $(* P<0.05$, compared with control).

Abbreviations: N-Ac-L-Leu-PEI, N-acetyl-L-leucine-polyethylenimine; SD, standard deviation; h, hour.

by the higher cytotoxicity of Lipofectamine ${ }^{\mathrm{TM}} 2000$, triggering the death of neighboring cells. Finally, we detected the inhibition of cell migration after DNAzyme transfection through Transwell migration assay, in which the representative images of migrated cells at the bottom of membrane were stained with crystal violet. As shown in Figure 11, the number of migrated cells was much lower in the cells treated with Lipofectamine ${ }^{\mathrm{TM}} 2000$ or $N$-Ac-L-Leu-PEI-mediated DNAzyme delivery, suggesting that the reduction of aurora kinase A could suppress the cell migration. Meanwhile, the expression level of MMP-9, a key regulator for cell migration, ${ }^{40}$ was dramatically decreased after DNAzyme transfection (Figure 7), which was probably associated with the inhibition of cell migration. 


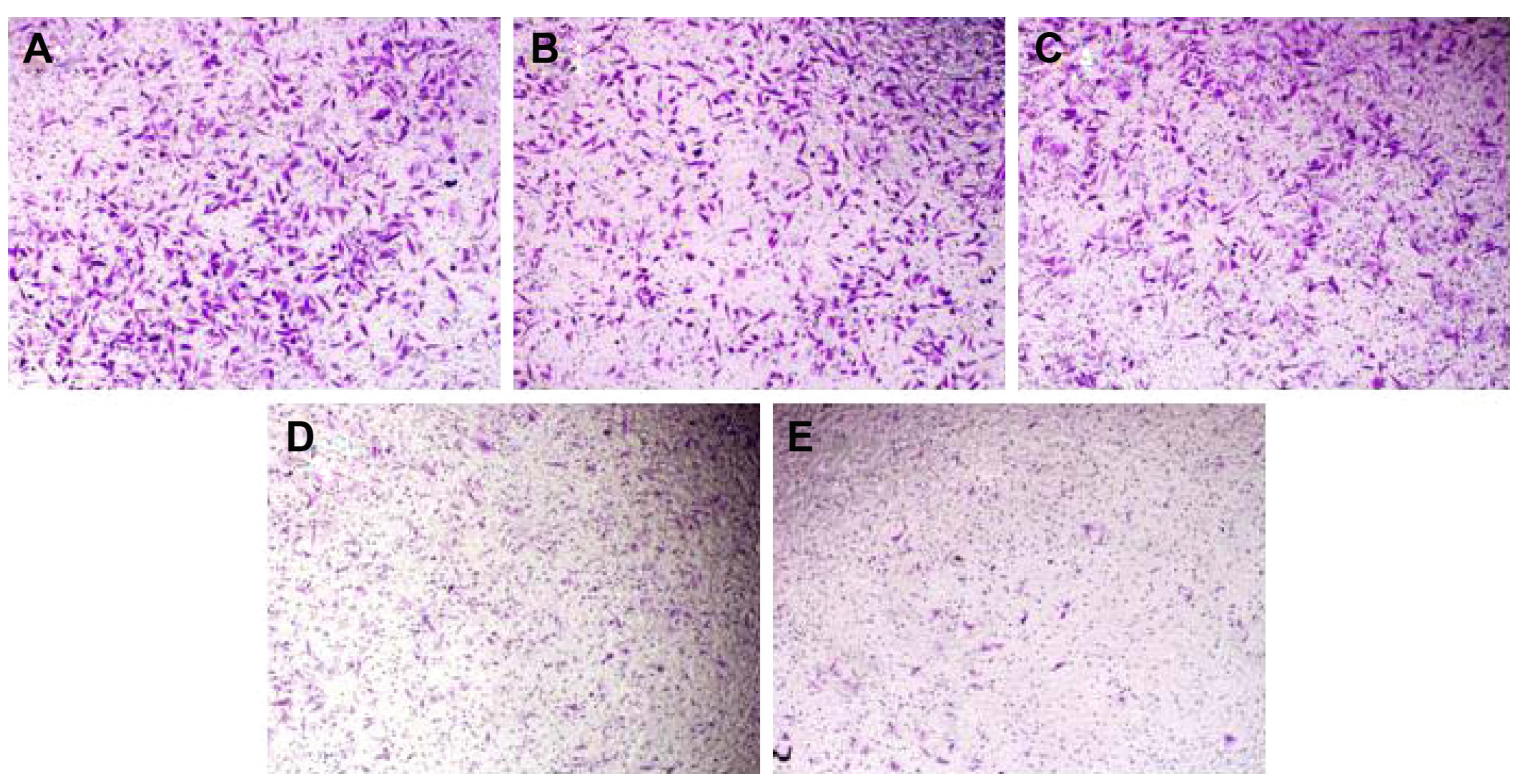

Figure II Effects of DNAzyme transfection on the cell migration using Transwell migration assay: (A) no treatment; (B) N-Ac-L-Leu-PEI; (C) N-Ac-L-Leu-PEl/iDz; (D) Lipofectamine ${ }^{\mathrm{TM}} 2000 / \mathrm{Dz}$; and (E) N-Ac-L-Leu-PEI/Dz.

Abbreviation: $\mathrm{N}$-Ac-L-Leu-PEI, $\mathrm{N}$-acetyl-L-leucine-polyethylenimine.

\section{Conclusion}

The derivative $N$-Ac-L-Leu-PEI could efficiently achieve the delivery of DNAzyme targeting aurora kinase A into tumor cells. Through the DNAzyme transfection, excessive proliferation and migration of tumor cells have been successfully inhibited. Thus, DNAzyme targeting aurora kinase A can potentially solve the most important problems of malignant tumors, and the PEI derivative-mediated DNAzyme delivery will be a promising therapeutic technique for treating cancers and other diseases.

\section{Acknowledgments}

The research was supported by Natural Science Foundation of China (Nos 21204025, 81373344, and 81473142), grants from the Science and Technology Department of Jilin Province (Nos 20130522005JH and 20140101140JC), and the Fundamental Research Funds for the Central Universities (JCKY-QKJC30).

\section{Disclosure}

The authors report no conflicts of interest in this work.

\section{References}

1. Siegel R, Ma J, Zou Z, Jemal A. Cancer statistics, 2014. CA Cancer J Clin. 2014;64:9-29.

2. Salinas CA, Tsodikov A, Ishak-Howard M. Prostate cancer in young men: an important clinical entity. Nat Rev Urol. 2014;11:317-323.

3. Gehrig S, Sami H, Ogris M. Gene therapy and imaging in preclinical and clinical oncology: recent developments in therapy and theranostics. Ther Deliv. 2014;5:1275-1296.
4. Vader G, Lens SM. The aurora kinase family in cell division and cancer. Biochim Biophys Acta. 2008;1786:60-72.

5. Bar-Shira A, Pinthus JH, Rozovsky U, et al. Multiple genes in human $20 \mathrm{q} 13$ chromosomal region are involved in an advanced prostate cancer xenograft. Cancer Res. 2002;62:6803-6807.

6. Lee EC, Frolov A, Li R, Ayala G, Greenberg NM. Targeting aurora kinases for the treatment of prostate cancer. Cancer Res. 2006;66: 4996-5002.

7. Qu Y, Zhang L, Mao M, et al. Effects of DNAzymes targeting aurora kinase A on the growth of human prostate cancer. Cancer Gene Ther. 2008; 15:517-525.

8. Katayama H, Sasai K, Kawai H. Phosphorylation by aurora kinase A induces Mdm2-mediated destabilization and inhibition of p53. Nat Genet. 2004;36:55-62.

9. Cheung CH, Sarvagalla S, Lee JY, Huang YC, Coumar MS. Aurora kinase inhibitor patents and agents in clinical testing: an update (2011-2013). Expert Opin Ther Pat. 2014;24:1021-1038.

10. Oh YK, Park TG. siRNA delivery systems for cancer treatment. $A d v$ Drug Deliv Rev. 2009;61:850-862.

11. Pereira DM, Rodrigues PM, Borralho PM, Rodrigues CM. Delivering the promise of miRNA cancer therapeutics. Drug Discov Today. 2013; 18:282-289.

12. Farooqi AA, Rehman ZU, Muntane J. Antisense therapeutics in oncology: current status. Onco Targets Ther. 2014;7:2035-2042.

13. Isaka Y. DNAzymes as potential therapeutic molecules. Curr Opin Mol Ther. 2007;9:132-136.

14. Tan ML, Choong PF, Dass CR. DNAzyme delivery systems: getting past first base. Expert Opin Drug Deliv. 2009;6:127-138.

15. Sclhubert S, Kurreck J. Ribozyme and deoxyribozyme strategies for medical applications. Curr Drug Targets. 2004;5:667-681.

16. Karnati HK, Yalagala RS, Undi R, Pasupuleti SR, Gutti RK. Therapeutic potential of siRNA and DNAzymes in cancer. Tumour Biol. 2014;35:9505-9521.

17. Pun SH, Tack F, Bellocq NC, et al. Targeted delivery of RNA-cleaving DNA enzyme (DNAzyme) to tumor tissue by transferring-modified, cyclodextrin-based particles. Cancer Biol Ther. 2004;3:641-650.

18. Tack F, Noppe M, Van Dijck A, et al. Delivery of a DNAzyme targeting c-myc to HT29 colon carcinoma cells using a gold nanoparticulate approach. Pharmazie. 2008;63:221-225. 
19. Chan CW, Khachigian LM. DNAzyme delivery approaches in biological settings. Curr Med Chem. 2013;20:3448-3455.

20. El-Aneed A. An overview of current delivery systems in cancer gene therapy. J Control Release. 2004;94:1-14.

21. Tian H, Chen J, Chen X. Nanoparticles for gene delivery. Small. 2013; 9:2034-2044.

22. Godbey WT, Wu KK, Mikos AG. Tracking the intracellular path of poly(ethylenimine)/DNA complexes for gene delivery. Proc Natl Acad Sci U S A. 1999;96:5177-5181.

23. Tian H, Lin L, Chen J, Chen X, Park TG, Maruyama A. RGD targeting hyaluronic acid coating system for PEI-PBLG polycation gene carriers. J Control Release. 2011;155:47-53.

24. Jones CH, Chen CK, Ravikrishnan A, Rane S, Pfeifer BA. Overcoming nonviral gene delivery barriers: perspective and future. Mol Pharm. 2013;10:4082-4098.

25. Patnaik S, Gupta KC. Novel polyethylenimine-derived nanoparticles for in vivo gene delivery. Expert Opin Drug Deliv. 2013;10:215-228.

26. Zhao Y, Yang R, Liu D, et al. Starburst low-molecular weight polyethylenimine for efficient gene delivery. J Biomed Mater Res A. 2012;100: 134-140.

27. Tian H, Li F, Chen J, Huang Y, Chen X. $N$-isopropylacrylamidemodified polyethylenimines as effective gene carriers. Macromol Biosci. 2012;12:1680-1688

28. Zheng M, Zhong Y, Meng F, Peng R, Zhong Z. Lipoic acid modified low molecular weight polyethylenimine mediates nontoxic and highly potent in vitro gene transfection. Mol Pharm. 2011;8:2434-2443.

29. Guo Z, Tian H, Lin L, et al. Hydrophobic polyalanine modified hyperbranched polyethylenimine as high efficient pDNA and siRNA carrier. Macromol Biosci. 2014;14:4106-4114.

30. Zhang J, Wu D, Xing Z, et al. $N$-Isopropylacrylamide-modified polyethylenimine-mediated $\mathrm{p} 53$ gene delivery to prevent the proliferation of cancer cells. Colloids Surf B Biointerfaces. 2015;129:54-62.
31. Li Z, Zhang L, Li Q. Induction of apoptosis on cancers cells through $\mathrm{N}$-acetyl-L-leucine-modified polyethylenimine-mediated p53 gene delivery. Colloids Surf B Biointerfaces. 2015;135:630-638.

32. Un K, Sakai-Kato K, Oshima Y, Kawanishi T, Okuda H. Intracellular trafficking mechanism, from intracellular uptake to extracellular efflux, for phospholipid/cholesterol liposomes. Biomaterials. 2012;33: 8131-8141.

33. Lo YL, Sung KH, Chiu CC, Wang LF. Chemically conjugating polyethylenimine with chondroitin sulfate to promote CD44-mediated endocytosis for gene delivery. Mol Pharm. 2013;10:664-676.

34. Dutertre S, Cazales M, Quaranta M, et al. Phosphorylation of CDC25B by aurora-A at the centrosome contributes to the G2-M transition. J Cell Sci. 2004;117:2523-2531.

35. Khalil IA, Kogure K, Akita H, Harashima H. Uptake pathways and subsequent intracellular trafficking in nonviral gene delivery. Pharmacol Rev. 2006;58:32-45.

36. Chiu YL, Ho YC, Chen YM, et al. The characteristics, cellular uptake and intracellular trafficking of nanoparticles made of hydrophobicallymodified chitosan. J Control Release. 2010;146:152-159.

37. Wiktorska M, Papiewska-Pająk I, Okruszek A, Sacewicz-Hofman I, Niewiarowska J. DNAzyme as an efficient tool to modulate invasiveness of human carcinoma cells. Acta Biochim Pol. 2010;57:269-275.

38. Wang F, Saran R, Liu J. Tandem DNAzymes for mRNA cleavage: choice of enzyme, metal ions and the antisense effect. Bioorg Med Chem Lett. 2015;25:1460-1463.

39. Marumoto T, Zhang D, Saya H. Aurora-A - a guardian of poles. Nat Rev Cancer. 2005;5:42-50.

40. Bauvois B. New facets of matrix metalloproteinases MMP-2 and MMP-9 as cell surface transducers: outside-in signaling and relationship to tumor progression. Biochim Biophys Acta. 2012;1825:29-36.
International Journal of Nanomedicine

\section{Publish your work in this journal}

The International Journal of Nanomedicine is an international, peerreviewed journal focusing on the application of nanotechnology in diagnostics, therapeutics, and drug delivery systems throughou the biomedical field. This journal is indexed on PubMed Central, MedLine, CAS, SciSearch ${ }^{\circledR}$, Current Contents ${ }^{\circledR} /$ Clinical Medicine,

\section{Dovepress}

Journal Citation Reports/Science Edition, EMBase, Scopus and the Elsevier Bibliographic databases. The manuscript management system is completely online and includes a very quick and fair peer-review system, which is all easy to use. Visit http://www.dovepress.com/ testimonials.php to read real quotes from published authors. 